\title{
I Seminário Sobre Biotecnologia e Ciência: Realidade e Fiç̧ão
}

DATA: 28 e 29 de abril de 2005

LOCAL: INSTITUTO NACIONAL DE CÂNCER

PRAÇA DA CRUZ VERMELHA, 23/8 andar - RIO DE JANEIRO

\section{PRESIDENTE DO FÓRUM:}

Dr. José Gomes Temporão

\section{ORGANIZAÇÃO :}

N úcleo de D esenvolvimento Tecnológico e Terapêutico. H C-I/IN CA

D ra. Raquel Ciuvalschi Maia

Dr. José Antonio de Oliveira

Prof. Pedro Carvalho Rodrigues

D ra. Regina M oreira Ferreira

\section{COMISSÃO CIENTÍFICA}

D ra. Claudete Esteves Klumb

Dr. H ector Seuanez

Dr. José Antonio de Oliveira

Dr. Luiz Claudio Thuler

D ra. M arisa Breitenbach

Prof. Pedro Carvalho Rodrigues

Dra. Raquel Ciuvalschi M aia

D ra. Regina M oreira Ferreira

\section{COMISSÃO EXECUTIVA}

D r. José Gomes Temporão - Diretor G eral do INCA

D ra. Eliana Claudia de O tero Ribeiro - Coordenadora de Ensino e D ivulgação Científica/IN CA

D ra. M arisa Breitenbach - Coordenadora de Pesquisa/IN CA

D ra. Rita Byington - D iretora do HC - I/IN CA

\section{OBJETIVOS}

- Discutir os avanços científicos que contribuem para o bem-estar da população e não ofereçam riscos para a saúde;

- Verificar as potencialidades de aplicação da biotecnologia na área do diagnóstico e tratamento do câncer;

- Discutir a acessibilidade das populações às novas tecnologias desenvolvidas;

- Discutir a formação de opinião pública com percepção crítica das tecnologias a serem desenvolvidas. 


\section{A presentação}

A proposta de realização do evento é a discussão dos aspectos médicos, diagnósticos e terapêuticos e políticas de formação científica e educacional. $\mathrm{H}$ á que se considerar que todas essas atividades deverão ser pensadas no sentido de se criar uma perspectiva crítica com relação ao custo-benefício e a aplicabilidade na saúde humana.

A biotecnologia tem semostrado um forte instrumento para promover o desenvolvimento científico etecnológico, em nível mundial. 0 potencial de aplicação da tecnologia é ilimitado com benefícios incalculáveis do ponto de vista econômico, médico e social. No futuro, a biotecnologia poderá contribuir significativamente para a prevenção e cura de diversas enfermidades. D oença como o câncer poderá de fato ser identificado antes mesmo de sua manifestação clínica resultando não só em terapêuticas precoces como até em medidas preventivas e eficazes. N 0 Brasil, diversas instituições públicas e privadas, têm desenvolvido pesquisas em biotecnologia, com geração de produtos e patentes, comparáveis aos países de primeiro mundo. $\mathrm{N} 0$ âmbito científico dois componentes merecem destaque: a necessidade da disseminação do conhecimento e as normas de segurança na pesquisa e aplicação destas.

\section{Raquel Ciuvalschi Maia José Antonio de O liveira Pedro Carvalho Rodrigues Regina M oreira Ferreira} $N$ úcleo de D esenvolvimento Tecnológico eTerapêutico H ospital do Câncer I - IN CA 


\section{Tecnologia e humanismo}

Leopoldo de Meis

Instituto de Bioquímica Médica, Universidade Federal do Rio de J aneiro

0 número de novas descobertas feitas nos últimos 150 anos cresceu de forma exponencial o que permitiu um entendimento cada vez maior dos princípios que regem a $\mathrm{N}$ atureza. $\mathrm{O}$ homem soube utilizar as novas descobertas em seu proveito para mudar radicalmente sua forma de viver. 0 cotidiano da nova era tecnológica requer dos jovens que entram no mercado de trabalho uma formação científica e tecnológica cada vez maior. 0 rápido avanço do conhecimento tem levado a (1) um distanciamento cada vez maior entre o fazer científico e os conceitos que ensinamos nas universidades, (2) um favorecimento da superespecialização e a compartimentalização do saber (3) uma dificuldade crescente de comunicação entre as diversas áreas do saber (4) um distanciamento cada vez maior entre os países desenvolvidos produtores do conhecimento e os países em vias desenvolvimento que necessitam e consomem o novo conhecimento. $\mathrm{N}$ este cenário, $\mathrm{O}$ afastamento entre as ciências humanas e as ciências exatas tem contribuído para o aprofundamento do conflito humano tecnológico característico dos tempos modernos. 


\title{
R elações entre novas tecnologias e a ficção-científica
}

\author{
leda Tucherman \\ Escola de Comunicação, Universidade Federal do Rio de Janeiro
}

Simulação é a palavra-chave que acompanha as novas tecnologias informacionais que servem de modelo para as biotecnologias e os estudos de genética entre outros. Sua principal característica é a possibilidade de criar realidades paralelas e inverter a clássica relação temporal: antecipando o futuro e tornando-o atual, dois mundos transformamse em co-presentes, ainda que sua realidade tenha uma natureza diferente. A ficção-científica, estilo narrativo filho da modernidade, expressa um paradoxo: o lugar onde convivem a liberdade e a ousadia da ficção com o rigor e a objetividade da ciência. Em suas narrativas literárias e cinematográficas fomos apresentados aos temas que, hoje, pertencem ao conjunto epistemológico tanto da filosofia contemporânea quanto das novas tecnologias e que podemos exemplificar como: as desconstruções múltiplas das diferenças entre natural e artificial, humano e nãohumano, vivo e não vivo, real e virtual, as mutações e transformações do corpo humano; as transformações do político assim como o fim da história e o fim dos tempos; os paradoxos temporais; a comunicação com inteligências demonstrando formas de vida totalmente diferentes. Atualmente os enunciados oriundos dos grandes laboratórios científicos e dos grandes centros universitários de pesquisa de ponta afirmam que vivemos num mundo de simulação e ficção: as próteses não são mais correções de handicap, mas possibilidades de expandir potencializações, assim como podemos, agora, por associações e conexões maquínicas e químicas, superar a Teoria da Evolução até a criação (quase) livre. Se a ficção-científica deveria "descrever a vida tal como não a conhecemos", hoje esta é a tarefa das novas tecnologias, o que explica que sejam as primeiras que estejam propondo os limites através das perguntas que encontramos em M etropolis (Fritz Lang), Blade Runner (Ridley Scott), Inteligência Artificial (Steven Spielberg), $M$ atrix (Wachowski) entre outros: quando o encontro do humano com o pós-humano acontecer será para melhor ou para pior? Até que limites podemos nos modificar e ainda permanecer humanos? 


\section{Benefícios e riscos da biotecnologia}

Eloi S. Garcia

Departamento de Bioquímica e Biologia Molecular, IOC, Fundação Oswaldo Cruz

0 genoma é a seqüência do ácido desoxirribonucléico (DN A) de um organismo. O DN A carrega os códigos para a síntese das proteínas. 0 proteoma representa as proteínas de um organismo vivo. Este tema de investigação pretende catalogar e caracterizar as proteínas derivadas do código genético, comparar as variações dos níveis de expressão em diferentes condições, estudar suas interações e identificar suas funções na célula. A melhor maneira de olhar uma doença é que ela seja definida pelo D N A. O conhecimento sobre os genes envolvidos em uma doença e a via metabólica ou o local de ação de um medicamento, leva à descoberta de novas possibilidades de alvos para uma droga. Assim, medicamentos também têm sido testados em vários tipos de câncer, lupus, H epatite C, deficiência de hormônio do crescimento, úlceras venosas crônicas, imunodeficiências, doenças cardiovasculares e osteoporoses, entre outras. Apesar desta promessa ser amplamente divulgada é ainda precipitado assumir que a genômica médica se tornará uma realidade. As prováveis novas vacinas serão contra citomegavírus, AIDS, doenças meningocócicas, Alzheimer, abuso de drogas, H PV, peste, certos tipos de câncer, Escherichia coli, doença de Lime, hepatites, Chlamydia, H eyicobacter, tuberculose, febre amarela, dengue, malária, resfriado comum, influenza, entre outras doenças. Foram divulgados genomas de 150 bactérias e 1.600 vírus, que estão sendo seqüenciados e disponibilizados para a comunidade científica. $\mathrm{N}$ os bancos de dados destes genomas encontram-se genes de proteínas interessantes, que são expressas na superfície destes microorganismos. Estes podem ser inseridos em bactérias. Estas bactérias transgênicas, além de suas proteínas, produzirão as moléculas baseadas nas instruções dos genes inseridos. Após serem isoladas, as proteínas escolhidas poderão ser testadas em animais. Esta é a vacinologiareversa, que pode realizar em poucos meses testes que demorariam mais de 30 anos pela metodologia convencional. A genética depende de um diálogo informado sobre as implicações ética, moral, social e riscos que resulta da multiplicidade de áreas envolvidas no desenvolvimento da pesquisa. As dúvidas sobre o acesso à população dos avanços genéticos contemporâneos são pontos que a sociedade necessita resolver nos próximos anos enfrentando as novas possibilidades das utilizações e promessas, implicações e riscos das descobertas de genômica e proteômica. 


\section{A era genômica}

Hector Seuanez

Divisão de Genética, Coordenação de Pesquisa, Instituto Nacional de Câncer

0 extraordinário avanço da biologia molecular, bioquímica e informática permite analisar o genoma humano de forma holística. No estudo das patologias tumorais, este enfoque abrangente tem permitido (1) identificar genes envolvidos nos processos tumorais, como aqueles que normalmente inibem a proliferação celular (genes supressores de tumor), os que ativam a proliferação (oncogenes) e os envolvidos no reparo do D N A; (2) identificar rearranjos genômicos, como aberrações cromossômicas características e perda de heterozigosidade; (3) realizar estudos funcionais em microarrays; (4) melhorar os métodos de diagnóstico e prevenção, assim como estratificar as doenças tumorais em base a uma taxonomia molecular. A identificação destes genes resulta da utilização de técnicas de mapeamento gênico, sequenciamento, identificação de mutações, experimentos de transfeç̧ão e caracterização de produtos protéicos. U m exemplo de um gene supressor de tumor é o RB1 cuja disfunção bialélica é responsável pelo retinoblastoma. $O A B L$ é um exemplo de um oncogene cuja disfunção ocorre na Leucemia M ieloide Crônica, onde este oncogene é rearranjado, formando um gene quimérico $B C R-A B L$. Um conjunto de sete genes de reparo de DNA, codificando helicases, endonucleases, polimerases e ligases são responsáveis por diferentes patologias, como xeroderma pigmentoso ou câncer colo-retal não-poliposo hereditário. A citogenética convencional e as técnicas de hibridização in situ com sondas fluorescentes (FISH) demonstraram a existência de rearranjos cromossômicos, enquanto que duplicações e deleções, no nível citogenético, também são detectadas por Comparative $\mathrm{G}$ enomic H ybridization ( $\mathrm{CGH}$ ). O utras perdas genômicas mais pontuais são demonstradas pela perda de heterozigosidade em regiões que contêm marcadores moleculares hipervariáveis (microssatélites de D N A). Em alguns tumores, como no câncer colo-retal não poliposo, a instabilidade genômica é caracterizada por muitas perdas pontuais no tecido tumoral quando comparado a tecidos normais do mesmo indivíduo. Finalmente, a funcionalidade de nosso genoma pode ser estudada de forma holística mediante mi croarrays, onde lâminas contendo sondas (probes) específicas são submetidas a uma hibridização competitiva com cD N As tumorais e normais marcados com fluorocromos diferentes. A detecção de genes expressos em diferentes tumores e a posterior quantificação dos transcritos por PCR em tempo real fornece um quadro muito completo da funcionalidade do genoma tumoral permitindo a estratificação de patologias previamente indistinguíveis pela análise genética pontual. 


\section{A conselhamento genético}

Fernando Regla Vargas

Divisão de Genética, Coordenação de Pesquisa, Instituto Nacional de Câncer

0 aconselhamento genético $(A G)$ é o processo de comunicação que lida com os problemas associados à ocorrência ou à possibilidade de ocorrência de um distúrbio genético em uma família. 0 AG oncológico relaciona-se com 0 câncer de caráter hereditário. D entre os tumores mais comuns de manifestação na vida adulta, al guns destacam-se por apresentarem uma pequena, porém definida, proporção de casos hereditários. N este grupo incluem-se 5 a $10 \%$ do total de casos de câncer de mama, câncer de ovário, câncer colo-retal, câncer de tireóide, melanoma e câncer de próstata. Além disto, certos tumores de ocorrência na infância podem ter caráter hereditário, como é o caso do retinoblastoma, tumor este considerado o paradigma do câncer familiar. $\mathrm{N}$ as duas últimas décadas uma série de síndromes de predisposição hereditária ao câncer (SPHC) foram descritas, que cursam com risco elevado de desenvolvimento de câncer. Em algumas SPH C este risco pode chegar a 100\%, como é o caso de câncer coloretal na polipose adenomatosa familiar (FAP), e o câncer de tireóide na síndrome de N eoplasias Endócrinas M últiplas Tipo 2. A identificação dos indivíduos portadores destas condições é importante por vários motivos: 1) porque estes indivíduos apresentam um risco alto de desenvolvimento de câncer, 2) porque freqüentemente outros familiares do indivíduo identificado com uma SPH C também apresentam alto risco de desenvolvimento de câncer, e 3) porque existem medidas de vigilância e/ou de prevenção que podem ser indicadas a este grupo de indivíduos I famílias, visando detecção precoce e/ou redução de risco de desenvolvimento de câncer. N este sentido, 0 objetivo principal do AG oncológico é a identificação dos indivíduos portadores de SPH C e planejamento das medidas de vigilância ou prevenção aplicáveis às diferentes situações de alto risco de desenvolvimento de câncer. Em muitas das SPH C os genes responsáveis foram identificados, possibilitando a realização de teste genético para a detecção de mutações germinativas nestes genes. Este teste tem um caráter preditivo, uma vez que o mesmo pode identificar indivíduos portadores de mutação germinativa, porém, que ainda não desenvolveram câncer. Juntamente com estes marcadores moleculares que podem identificar indivíduos com alto risco de desenvolvimento de câncer, a história familiar permanece como uma das ferramentas mais efetivas e de melhor custo-benefício para a identificação destes indivíduos. 


\section{Proteoma do câncer}

Eliana Abdelhay e Luciana Pizzatti

Divisão de Laboratórios, Centro Nacional de Transplante de Medula Óssea,

Instituto Nacional de Câncer

O câncer é em geral o resultado de uma mutação genética somática. Esta mudança genética leva a alterações do padrão de expressão gênica da célula modificando sua biologia. $\mathrm{N}$ os últimos anos, com o término do sequenciamento do Genoma H umano, diversas técnicas foram desenvolvidas com o objetivo de analisar a expressão gênica de tecidos e tipos celulares, principalmente em câncer. Com estas tecnologias diversos estudos de expressão diferencial entre amostras de células normais e doentes foram feitos, e em muitos deles, marcadores de expressão tumoral importantes foram encontrados. Entretanto, a análise exclusiva do transcriptoma da célula não indica se o gene diferencialmente expresso irá traduzir realmente uma proteína com função tumoral ou não. Por outro lado, o Proteoma pode ser definido como o conjunto de proteínas expressas por um genoma e, portanto, representa toda a informação genética que está sendo expressa em um determinado momento ou condição patológica. Em relação às diferentes neoplasias o Proteoma de Leucemias pode ser destacado uma vez que a obtenção de material de neoplasias hematológicas oferece menores dificuldades e o número de variáveis possíveis de análise é elevado. A leucemia mielóide crônica é uma desordem hematológica, que tem como marcador, o cromossomo Ph gerado a partir da translocação $t(9 ; 22)$. O s transcritos quiméricos codificam para uma proteína de 210kD a que possui uma atividade alterada de tirosina quinase, responsável pelo fenótipo da doença. D iversas interações moleculares podem contribuir para a alteração do comportamento celular das células leucêmicas, induzindo a proliferação ilimitada, defeitos de maturação e redução de adesão das células ao estroma medular. N este trabalho, tivemos como objetivo identificar as modificações na expressão protéica de pacientes na fase crônica da leucemia mielóide crônica. U tilizamos como abordagem o estudo Proteômico comparativo. Através da eletroforese bidimensional de alta resolução (2D -M ultiphor II Electrophoresis System -Amersham Bioscienses) analisamos e identificamos os padrões protéicos de células mononucleares de medula óssea de doadores normais. As proteínas presentes nestes padrões foram retiradas e identificadas por espectrometria de massas usando a tecnologia M ALDI-TOF (Voyager DEApplied biosystens). Estes resultados estabeleceram o padrão protéico das células mononucleares da medula óssea normal. A mesma análise foi feita com amostras de medula óssea dos pacientes e os padrões protéicos gerados e identificados foram comparados com o padrão protéico da medula óssea normal. Foram identificadas 250 proteínas e, entre elas, 31 proténas diferencialmente expressas nos pacientes. D estacamos as proteínas: M yc binding protein 1, 53BP1, M dm4, O SBP-related protein 3 e M ortalin como putativos alvos para a sinalização promovida por $B C R-A B L$. 


\section{Nanotecnologia: ciência multidisciplinar}

Nelson Duran Rede de Nanobiotecnologia do MCT/CNPq, Instituto de Química da Universidade Estadual de Campinas (IQ-UNICAMP), e Núdeo de Ciências Ambientais e do Centro Interdisciplinar de Investigações Bioquímicas da Universidade de Mogi das Cruzes (UMC)

Talvez a melhor forma de explicar a multidisciplinaridade da nanotecnologia é mostrar como se desenvolveu uma rede de nanobiotecnologia no Brasil. Após quase dois anos de atividades, a Rede de N anobiotecnologia do M CT/ CN Pq, integrada por 19 universidades e institutos de pesquisa do Brasil, mostra sinais claros de maturidade e consolidação. N esse período, a equipe de 294 integrantes das mais variadas áreas do conhecimento, como Q uímica, Física, M edicina, Farmacologia, Biologia, Bioquímica, Engenharias, Biotecnologia, etc. contando com 92 pesquisadores e 202 alunos desenvolveu ou concluiu 7 produtos e 2 processos farmacêuticos, 3 produtos biotecnólogicos, 4 biossensores e equipamentos, e aproximadamente 700 trabalhos publicados. Vinte patentes foram aprovadas e outras 14 submetidas. Recentemente ampliado, com mais 3 novos subprojetos, o trabalho da Rede levou também a 2 produtos desenvolvidos repassados à indústria, além de 6 projetos em conjunto. 0 s passos seguintes pressupõem a ênfase no suporte de infra-estrutura, para que outros processos bem-sucedidos em escala laboratorial possam atrair o interesse industrial. 0 utra questão a ser estudada com urgência é 0 aspecto regulatório dos novos fármacos, já que a maioria das formulações melhoradas ou rejuvenescidas por meio da micro e nanotecnologia já são conhecidas. 0 avanço da nanobiotecnologia, por ser rápido, exige decisões igualmente rápidas, para a indústria farmacêutica nacional poder inovar e competir no mercado mundial.0 utro ponto de extrema importância diz respeito às patentes relacionadas a invenções apoiadas por órgão de fomentos e desenvolvidas pela universidade e pelas indústrias. A quem se deve deixar a negociação das patentes, à universidade, à indústrias ou aos órgãos de fomento à pesquisa e inovação? A experiência da Rede tem mostrado que as empresas não se opõem ao pagamento de royal ites às universidades ou aos órgãos de fomento, uma vez livre dos atual mente excessivos empecilhos administrativos. 


\section{Nanobiomagnetismo e saúde}

Zulmira G.M. Lacava

Instituto de Ciências Biológicas, Universidade de Brasília

M anipulando a matéria em escala nanométrica, a nanobiotecnologia tem o potencial de revolucionar amplamente vários campos tecnológicos e científicos, podendo levar, por exemplo, à formulação de novos carreadores de drogas, com auto-vetorização e/ou com vetorização assistida, permitindo liberação controlada e sustentada de fármacos e redução de efeitos colaterais. $\mathrm{H}$ oje é bastante plausível o uso de nanossistemas para veiculação de drogas e tratamento de inúmeras doenças, como os que se baseiam em lipossomos, nanopartículas e nanocompósitos, os quais ficam especialmente interessantes se forem construídos a partir de materiais magnéticos. U ma simples injeção pode liberar milhares de partículas magnéticas na corrente sangüínea de uma pessoa. Estas partículas podem ser conduzidas para uma região específica do corpo por meio de uma configuração de campo magnético externo. U ma das aplicações possíveis para este sistema é o transporte de drogas quimioterápicas especificamente para a área de interesse (tumor, por exemplo), sem que essas drogas afetem os tecidos normais. É uma forma de obter-se a maximização do efeito da droga, minimizando seus efeitos colaterais. U ma outra aplicação interessante para as nanopartículas magnéticas advém da possibilidade de associá-las a anticorpos que se ligariam às células tumorais, aumentando a sensibilidade em exames de ressonância magnética, e assim proporcionando um diagnóstico mais precoce de metástases tumorais, aumentando as chances de que 0 tratamento para 0 câncer proporcione um resultado favorável para o paciente. 0 utra vantagem deste método é que, uma vez detectada a presença de células tumorais por sua associação com as nanopartículas magnéticas, pode-se submetêlas à ação de um campo magnético externo ao organismo. A interação das nanopartículas magnéticas com o campo externo aplicado dissipará calor nas células tumorais associadas, provocando sua lise e morte. Este processo conhecido como magnetohipertermia é uma aplicação promissora dos processos nanobiomagnéticos, pois leva à destruição específica de células cancerosas, sem afetar as células normais dos tecidos vizinhos. Esta estratégia pode também fazer com que a quimioterapia, radioterapia e terapia fotodinâmica sejam muito mais eficientes. Liderada pela Universidade de Brasília, esta pesquisa em nanobiomagnetismo é alvo de pesquisadores que integram a Rede de Pesquisa em $\mathrm{N}$ anobiotecnologia (MCT/CN Pq). 


\section{Nanotecnologia e sociedade}

Paulo Roberto Martins

Instituto de Pesquisas Tecnológicas-IPT - Coordenador da Rede de Pesquisa em Nanotecnologia, Sociedade e Meio Ambiente- RENANOSOMA

A nanotecnologia é tida por muitos como a portadora de uma nova revolução industrial. $M$ as, a nanotechnologia não está acima das críticas. Entre as diversas incertezas sobre esta tecnologia podemos apontar a toxicidade das partículas nano e sua necessidade de uma específica regulação. Embora possa ser entendida como uma nova tecnologia, ela porta questões éticas já observadas na biotecnologia. Assim, a questão que se coloca é se poderemos trabalhar as coisas de forma diferente às ocorridas com a biotecnologia. $\mathrm{O} u$ a nanotecnologia inevitavelmente se tornará o "G M O "? Será que iremos romper com o ciclo dos transgênicos em termos de propaganda, segredo (falta de transparência), medo e conflito, levando-se em consideração as preocupações sociais e ambientais desde 0 início? U ma das maiores lições da biotecnologia é que não são só os riscos atrelados a novas tecnologias que causam preocupações na população. Controvérsias crescem quando não se permite a participação do público neste processo. A este não é dada a oportunidade de perguntar: para que serve esta tecnologia? Q uem será seu proprietário ou irá se apropriar dela? Q uem irá se responsabilizar se as coisas não derem certo? Em quem nós podemos confiar? Q uem serão os incluídos e os excluídos? Presentemente já é comum ouvirmos a expressão "exclusão digital" e programas governamentais de "inclusão digital". Será que no futuro próximo ouviremos falar dos "nanoexcluídos"? Claro que todas estas questões pontuadas acima não devem ser resolvidas exclusivamente pelos técnicos, por aqueles que "entendem do assunto" pois não são questões técnicas. Para resolvê-las, o público deve ser envolvido deste o início. Exatamente enquanto a nanotecnologia está dando seus primeiros passos é que deve-se começar o debate com o público, colocando todas estas questões na mesa, de forma transparente. Aquele que serve como fonte de recolhimento de recursos para a pesquisa, deve servir também para indicar a direção que a pesquisa deve tomar no país. 


\title{
Transgênicos: biofábrica de fármacos
}

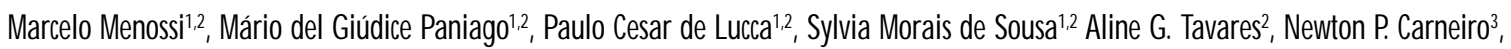 \\ Cynthia S. Horn ${ }^{4}$, José Andrés Yunes ${ }^{1,5}$, Paulo Arruda ${ }^{1,2}$ \\ ${ }^{1}$ Centro de Biologia Molecular e Engenharia Genética, UNICAMP \\ ${ }^{2}$ Departamento de Genética e Evolução, I.B., UNICAMP, \\ ${ }^{3}$ Centro Nacional de Pesquisa de Milho e Sorgo, Embrapa, Sete Lagoas, \\ ${ }^{4}$ Fundação Oswaldo Cruz, Instituto de Pesquisa Clínica Evandro Chagas \\ ${ }^{5}$ Centro Infantil Boldrini, Campinas
}

Há milênios a manipulação genética vem sendo realizada para o melhoramento de plantas. Essa manipulação estava limitava a cruzamentos entre plantas da mesma espécie ou espécies aparentadas até que a característica desejada fosse introduzida e fixada. Posteriormente foram utilizados agentes mutagênicos, como a radiação, para produção de mutações que geravam novas características. A pesar de terem revolucionado a relação entre o homem e natureza, essas tecnologias apresentam limitações, pois o processo é lento, restrito à possibilidade de cruzamento ou ao aparecimento da característica por mutações aleatórias. 0 desenvolvimento da tecnologia do D N A recombinante e da biotecnologia trouxeram novas ferramentas que possibilitam flexibilidade quase total na escolha da característica a ser introduzida, permitindo a criação de combinações sem a limitação dos cruzamentos. U ma das mais promissoras aplicações consiste na utilização de plantas para a produção de proteínas de interesse farmacológico e/ou industrial. Por apresentarem uma maquinaria pós-traducional semelhante à de mamíferos, custos de produção reduzidos e baixo risco à saúde humana, o uso de plantas poderá viabilizar a produção de proteínas antes indisponíveis comercialmente. U tilizando um cassete de expressão específico para sementes, nós desenvolvemos plantas de milho capazes de produzir Hormônio de $\mathrm{C}$ rescimento $\mathrm{H}$ umano ( $\mathrm{hGH}$ ) e Pró-insulina H umana em grandes quantidades. Adicionalmente, nosso grupo vem procurando obter plantas que já produzam a Insulina H umana na sua forma madura, bem como plantas que produzem o antígeno APA (AlanineProline-Rich Antigen), que poderá ser usado como vacina contra o M ycobacterium tuberculosis, o agente causador da tuberculose. 


\section{Transgênicos: riscos e benefícios}

Victor Augustus Marin

Setor de Biologia Molecular, Departamento de Microbiologia, INCQS, Fundação Oswaldo Cruz

0 homem tem alterado a composição genética das cultivares que utiliza há 10.000 anos. A seleção feita pelo homem para obter cultivares com melhores qualidades alterou drasticamente a espécie, quando comparado com seus parentes selvagens e até a redescoberta das leis de $M$ endel, não tínhamos base científica para a compreensão da "maquinaria genética". Através da engenharia genética, obtemos as chamadas plantas transgênicas, iniciando uma nova fase na Biotecnologia, a Biotecnologia M oderna. A grande diferença entre este tipo de melhoramento e os outros métodos, é que o gene inserido pode ser de outra espécie ou até mesmo de reinos diferentes. Para se obter uma planta transgênica são necessárias várias etapas, como: a identificação do gene de interesse a ser inserido; a clonagem deste gene; a transferência para o tecido da planta e a obtenção da planta transgênica através da cultura de tecidos vegetais e depois serem efetuados todos os testes ecológicos, agronômicos e de segurança alimentar. Estabeleceu-se que o alimento transgênico deve ser tão seguro para a saúde humana (ou animal) como o seu análogo convencional, considerando as modificações intencionais bem como as não intencionais que 0 alimento possa conter. 0 princípio inicial estabelecido é o da chamada "Equivalência Substancial", onde se um alimento ou ingrediente alimentar derivado dos recentes avanços em biotecnologia for considerado substancialmente equivalente a um alimento ou ingrediente alimentar convencional, aquele alimento poderá ser considerado tão seguro quanto este. $\mathrm{N}$ o entanto, no futuro, existirão derivados que não serão substancialmente equivalentes ao seu análogo convencional ou não terão análogo convencional e a eqüivalência substancial não será aplicada. N o Brasil, os produtos contendo acima de $1 \%$ de transgênicos deveriam estar rotulados desde abril de 2004 . H oje, no mercado mundial, existem em torno de 90 tipos de cultivares de plantas transgênicas aprovadas para consumo humano e/ou para ser utilizado na ração animal, não sendo computados os microrganismos e animais transgênicos existentes. $\mathrm{N}$ ão podemos generalizar e dizer que os transgênicos são bons ou ruins. D eve-se avaliar caso a caso, ou seja, transgênico por transgênico e sempre com base em pesquisas científicas e não com base em ideologia pró ou contra. 


\section{Situação de desenvolvimento tecnológico e produção de vacinas no Brasil}

Akira Homma

Bio-Manguinhos, Fundação Oswaldo Cruz

A erradicação da varíola ocorrida no Brasil, em 1973, foi um marco fundamental que possibilitou subseqüente criação do Programa N acional de Imunização (PNI) pelo M inistério da Saúde. No início, o PN I disponibilizava vacinas apenas contra 6 doenças imunopreveníveis e, gradativamente foi incorporando outras, para atingir 13 doenças, imunizando crianças, adolescentes e idosos. É hoje, o programa de imunização mais importante dentre os países em desenvolvimento. $\mathrm{N}$ o entanto, o Brasil não acompanhou os avanços tecnológicos da área e encontravase completamente despreparado para enfrentar a grande epidemia da meningite meningocócica ocorrida nos inícios da década de 70. Então, o governo federal resolveu fortalecer algumas instituições de pesquisa e tecnologia do país. Bio-M anguinhos/Fiocruz foi criado especificamente para desenvolvimento e produção de imunobiológicos necessários para Saúde Pública. N os inícios da década de 80, ocorreu outro evento que fez o governo fortalecer a participação pública nas atividades de produção de vacinas, que foi a decisão tomada pela Sintex do Brasil de abandonar abruptamente as atividades de produção de vacinas e soros, deixando o país em uma situação calamitosa. Foi então criado o Programa de Auto-suficiência Nacional em Imunobiológicos, que investiu durante mais de 15 anos, cerca de U S140 milhões de dólares, na modernização dos laboratórios públicos produtores de vacinas e soros do país. A implementação de políticas e estratégias corretas, de forma contínua e sistemática durante anos, erradicou a varíola na década de 70. H á 14 anos eliminou a poliomielite e há 4 anos 0 sarampo. 0 utras doenças imunopreveníveis têm notificação mais baixa da história de Saúde Pública do país. N este contexto, os laboratórios públicos produtores de vacinas vêm desempenhando papel estratégico. Todas vacinas incluídas no calendário básico deimunização são produzidas ou estão no processo de ter o domínio das tecnologias de produção, conseguindo conquistar a confiabilidade e credibilidade junto ao PN I. É o governo e a sociedade, garantindo o suprimento de vacinas de alta qualidade, em quantidade e no período compromissado. As atividades de inovação tecnológica, fundamentais para o futuro do país nesta área também vêm sendo apoiadas pelas agências governamentais de fomento, permitindo antever-se o desenvolvimento autóctone de algumas vacinas e imunobiológicos importantes para o país. 


\section{Dendritic cells vaccine}

José Alexandre Barbuto

Universidade de São Paulo

Dendritic cells (DC) are the most effective initiators of immune responses and their generation in vitro has renewed the interest in immunotherapy of cancer. Indeed, many promising clinical results have been achieved and much is still expected. H ere we describe the results of a protocol using autologous tumor and allogeneic dendritic hybrid cell vaccination every 6 weeks, with at least two doses, for metastatic melanoma and renal cell carcinoma patients. Seventy patients were enrolled between M arch 2001 and D ecember 2004. H alf of the patients received the vaccine alone (until $M$ arch 2003), and the other half received a single dose of cyclophosphamide before each vaccine dose and, after the second vaccine dose, a 5-day course of low dose IL-2 starting at the vaccination day. In each group 30 patients received the intended treatment of, at least, two vaccine doses. Response rates and patterns were not significantly different between the two groups. Though all patients included presented large tumor burdens and progressive diseases, $82 \%$ of them experienced clinical ben efit from the vaccination, with disease stabilization up to more than 22 months. The median time to progression was 5.7 months and no significant untoward effects were noted. Furthermore, immune function, as evaluated by cutaneous delayed-type hypersensitivity reactions to recall antigens and by peripheral blood proliferative responses to tumor-specific and non-specific stimuli, presented a clear tendency to recover in vaccinated patients. Also, dendritic cell differentiation and function showed a significant recovery in the vaccinated patients. These data indicate that dendritic-tumor cell hybrid vaccination affects the natural history of advanced cancer and provides support for its study in less advanced patients, who should, more likely, benefit more from this approach. 


\title{
DNA vaccines against $H$ uman papillomavirus-16 expressing a fusion polypeptide of the $E$ 6/E 7 oncoproteins and the glycoprotein $D$ from H uman herpes virus-1
}

Luís Carlos de Souza Ferreira

Laboratório do Departamento de Microbiologia, Universidade de São Paulo

\begin{abstract}
Cervical cancer is a leading cause of cancer deaths in women worldwide claiming approximately $300.000-400.000$ lives each year. Virtually all cases of cervical cancers are associated with persistent H uman papillomavirus (H PV) infections. N umerous studies have reported on vaccines targeting cancers induced by H PV-16 and most of them focused on the E 7 and E6 oncoproteins. D N A vaccines are appealing for active immunotherapy of cervical cancer as they induce a full spectrum of adaptive immune responses including CD 8+ cytolytic $T$ cells. In this work we report the development of DNA vaccines encoding the H PV-16 E6 and E7 oncoproteins genetically fused to the H uman herpes virus type 1 (H SV-1) gD protein for induction of T cell-mediated immunity and protection against tumor cell challenge. H ybrid genes, generated after insertion E6 or E 7-encoding sequences into internal sites of the $\mathrm{gD}$ gene, were in vitro transcribed and the chimeric proteins expressed on the surface of in vitro-transfected mammalian cells. Female C 57BL/6 mice immunized with intramuscular doses (100 $\mu \mathrm{g}$ of D N A/dose) of the D N A vaccines encoding $E 7$, but not those immunized with the vector encoding the $E 6$ oncoprotein, efficiently generated specific CD 8+T cells. Vaccination of mice with the D N A vaccines encoding the E7, or both E6 and E 7, conferred complete protection against challenge with TC-1 tumor cells. E7/gD -based DN A vaccines also induced partial protection (40\%) in a post-challenge vaccination model in which mice were injected with TC -1 cells on the same day or 5 days prior to the first vaccine dose. Based on these results $D N A$ vaccines encoding hybrid E7/gD proteins represent a promising approach both for prophylatic and therapeutic control of cervical cancer.
\end{abstract}




\section{Células-tronco da medula óssea de adultos}

Marco A. Zago

Centro de Terapia Celular, Faculdade de Mediana de Ribeirão Preto

A medula óssea do adulto contém uma grande diversidade de células. Além das células hematopoéticas em diferentes fases de diferenciação, adipócitos, células estromais e endoteliais, e osteoblastos, existem duas populações de células-tronco adultas: células tronco-hematopoéticas e células-tronco mesenquimais. Ambos tipos celulares são bastanteraros, contribuindo com menos de $0,1 \%$ das células nucleadas, e podem ser isoladas, cultivadas e estimuladas a diferenciar-se in vitro e in vivo. As células tronco hematopoéticas são mais abundantes na população de células CD 34+ (marcador que elas compartilham com células endoteliais), podendo ser obtidas de outras fontes como 0 sangue de cordão umbilical, e diferenciam in vitro originando colônias eritróides, de granulócitos-monócitos ou mistas. N ossos estudos concentram-se na comparação das propriedades, em especial da expressão gênica, entre células C D 34+obtidas de diferentes fontes, enafase precoce da diferenciação, buscando identificar genes relacionados com o comprometimento da célula primitiva no sentido eritróide ou monocítico-granulocitário. Já as células mesenquimais podem ser obtidas de um grande número de tecidos adultos e fetais. Com base na expressão gênica nós demonstramos que as células obtidas dessas diferentes fontes são similares, apesar de discretas diferenças funcionais, assim como são idênticas aos fibroblastos. Q uando provocada sua diferenciação osteoblástica ou adipocítica, ocorrem ativações e silenciamento ordenado de genes, mas o perfil global de expressão gênica não sofre modificações tão significativas. A identificação de características moleculares dessas células representa uma etapa central para aproveitar ou modificar suas características biológicas para finalidades terapêuticas.

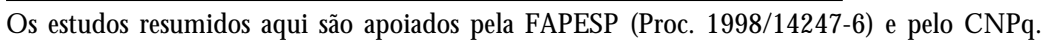




\title{
Células-tronco em doenças neurológicas
}

Rosalia Mendez-Otero

Instituto de Biofísica Carlos Chagas Filho, Universidade Federal do Rio Janeiro e Instituto do Milênio de Bioengenharia Tecidual

\begin{abstract}
Até recentemente acreditava-se que o Sistema N ervoso Central (SNC) adulto não tinha capacidade de regenerar após sofrer lesões ou injúrias e as funções exercidas pelas células ou processos lesados estariam irreversivelmente perdidas. Estudos recentes mostraram que os axônios do SN C apresentam uma certa regeneração, mas fatores presentes no meio impedem o sucesso desta regeneração. Além disto, foi mostrado que novos neurônios são gerados em regiões restritas do SN C durante toda a vida do indivíduo e estas observações abrem possibilidades interessantes de aplicações clínicas. N o entanto, a regeneração axonal e a neurogênese no adulto não são suficientes para regenerar amplas lesões no SN C e mais recentemente tem se investigado a possibilidade de se substituir neurônios perdidos através do uso de terapias celulares com células-tronco (CT). CT são células capazes de autorenovação e diferenciação em múltiplas linhagens e podem ser obtidas de diversas fontes como blastocistos, fetos ou tecidos adultos. A utilização de células-tronco fetais ou embrionárias levanta uma série de questões éticas/legais e científicas que impedem ainda o seu uso em pacientes. As células-tronco adultas são células indiferenciadas presentes em um tecido diferenciado. As células-tronco adultas são raras, difíceis de identificar e purificar e proliferam mais lentamente do que as células tronco embrionárias. 0 s protocolos clínicos que estão sendo avaliados no momento utilizam células-tronco adultas provenientes da medula óssea. Estas células apresentam a grande vantagem de serem obtidas do próprio paciente o que elimina as questões éticas/legais e a rejeição e em estudos experimentais apresentam uma grande plasticidade o que faz com tenham sido usadas em terapias celulares para lesões do sistema cardiovascular e nervoso. N esta apresentação faremos uma revisão dos protocolos clínicos que têm utilizado células-troncas adultas de medula óssea para tratar doenças neurológicas.
\end{abstract}




\title{
Células-tronco embrionárias: expectativas e realidade
}

Lygia da Veiga Pereira

Laboratório de Genética Molecular do Departamento de Biologia, Instituto de Biociências, Universidade de São Paulo

\begin{abstract}
A luta pela aprovação do Projeto de Lei de Biossegurança, liberando o uso de embriões humanos para a extração de células-tronco (CT) embrionárias, gerou enorme expectativa na população. M as agora que a poeira do sensacionalismo baixou, quais são as reais possibilidades das CT embrionárias? I dentificadas na década de 1980 em camundongos, as CT embrionárias são o tipo mais versátil de CT até hoje identificadas em mamíferos, possuindo a formidável capacidade de dar origem a todos os tecidos do corpo. Q uando diferenciadas in vitro e transplantadas em animais doentes, as CT embrionárias foram capazes de aliviar os sintomas de diversas doenças, desde leucemia e doença de Parkinson até paralisia causada por trauma da medula espinhal. As primeiras linhagens de CT embrionárias humanas surgiram em 1998, e junto com elas a enorme expectativa de seu uso terapêutico. Porém, antes disso temos algumas questões fundamentais que devem ser resolvidas: segurança (quando injetadas em camundongos em seu estado indiferenciado, essas células podem formar tumores); compatibilidade entre as CT embrionárias e o paciente (que poderia ser solucionado com a clonagem terapêutica - porém, esta foi proibida no Brasil); estabilidade de seu genoma (essas células tendem a desenvolver aneuploidias). N o Brasil, alguns grupos de pesquisa já trabalham com CT embrionárias de camundongo há algum tempo. Estes grupos estão capacitados a iniciar pesquisas agora com as células humanas. Q uanto à clonagem terapêutica, a colaboração entre grupos que fazem clonagem animal e aqueles que trabalham com CT embrionárias poderia tornar esta prática uma realidade no país. E enquanto não podemos utilizá-las como agente terapêutico, temos muito a aprender em pesquisa básica sobre a pluripotência das CT embrionárias. Apesar do uso terapêutico da CT embrionárias ainda estar longe de se tornar uma realidade, para que exista alguma chance disso um dia acontecer, precisamos pesquisar - e foi este direito que adquirimos com a aprovação do PL de Biossegurança. O Brasil já demonstrou competência nas pesquisas com CT de medula e de cordão umbilical, e agora poderemos fazer o mesmo com as CT embrionárias.
\end{abstract}




\title{
Clonagem e células-tronco: aspectos éticos, legais e filosóficos
}

\author{
Marco Segre \\ Faculdade de Mediana da Universidade de São Paulo
}

\begin{abstract}
Este relatório enfocou o aspecto ético nodal da utilização de embriões humanos para fins terapêuticos. 0 cerne da questão, a nosso ver, é o "status" que se quer conceder ao embrião concebido em laboratório, visando a esse objetivo específico. A preocupação deste relator foi a de enfocar a mencionada questão conceitual à luz de uma reflexão bioética que ele denomina "autônoma" (Ética da Reflexão Autonoma - E.R.A), no sentido dela não se prender a condições apriorísticas referentes ao momento do início da vida e "status" do embrião. Face às premissas supra, está clara nossa posição francamente favorável à utilização de células-tronco, a partir de pré-embriões produzidos "in vitro", sejam eles resultantes de fecundação ou de clonagem. A importância desse avanço científico e tecnológico tem, ao que tudo indica, enorme valor terapêutico. A possibilidade de se tratarem (e curarem) doenças como leucemias, mal de Parkinson, Alzheimer, a par de se poderem desenvolver órgãos que possam ser utilizados em transplantes, é uma perspectiva alentadora no sentido de melhorar a qualidade, e alongar o tempo de vida de muitas pessoas. 0 poder de decisão quanto ao destino desses pré-embriões é questão também importante, parecendo-nos apropriado que ele deva ser de seus "pais". Esta não é uma "questão menor", pois está em jogo a autonomia dos "doadores de células", embora ela deva ser posta depois da discussão conceitual de "a partir de quando se respeite um conjunto de células como vida humana". Concluindo, queremos que esteja transparente que não é nossa pretensão, com as reflexões expostas, ofender os juízos sobre valores de pessoas, grupos étnicos ou religiões. M uito menos de criar normas coerentes com nossas posições. N em poderíamos. O s progressos científicos serão aceitos ou recusados segundo os já mencionados fatores culturais e/ou religiosos. De forma tão democrática quanto possível. M as também entendemos ser nosso papel, na bioética, o de expor e defender posições que considerarmos importantes para a vida e a saúde humana.
\end{abstract}




\title{
Da descoberta ao seu relato: a divulgação da ciência
}

\author{
Jornalista Claudia J urberg \\ Fundação Oswaldo Cruz e Universidade Federal do Rio J aneiro
}

As inúmeras reportagens publicadas no noticiário brasileiro nos últimos meses sobre os potenciais terapêuticos que as células-tronco embrionárias poderão oferecer no futuro, aos mais variados pacientes foram, com certeza, 0 passaporte para a aprovação pelo Legislativo, dessas pesquisas em solo nacional. Se por um lado, a ciência desperta, no grande público, esperanças para um mundo melhor e a cura para doenças. Por outro, diversas apreensões relacionadas ao tema desencadeiam uma série de efeitos no imaginário coletivo. $\mathrm{N}$ o percurso, onde 0 marco inicial da divulgação científica é apontado para o secretário da Royal Society, H enry O Idenburg (1677), analisamos a corte Joanina, especialmente no que tange à sua chegada ao Brasil, à abertura dos portos e à liberação para que os jornais circulassem livremente, embora muitos fossem impressos na Inglaterra. E por fim, abordamos o panorama da divulgação científica nos dias atuais. A pós este breve relato histórico, que traça um paralelo entre a divulgação científica empreendida no mundo e no Brasil, analisamos os alguns fatos e as manchetes que marcaram época na imprensa e que foram, ao longo das últimas décadas, importantes para a compreensão de temas científicos atuais. D entro deste âmbito, discutiremos o papel da imprensa nas sociedades modernas e ressaltamos que, apesar da sua indiscutível função de transmissão do conhecimento, o ponto de ebulição entre jornalistas e cientistas permanece nas discussões recorrentes sobre fissão ou fusão de ambos os saberes. Embora façamos parte de campos profissionais diferentes com práticas distintas, acreditamos em complementaridade. Afinal, depois de tantas experiências nessa tentativa ao longo das últimas décadas de estreitar o diálogo entre cientistas e jornalistas, qual é o resultado? e qual é a próxima meta? Pretendemos sugerir alguns caminhos, sem contudo abdicar de uma postura crítica em relação às dificuldades e de um olhar atento aos direitos e aos deveres que têm os cidadãos pertencentes à sociedade da informação, perpassando os campos da bioética, da biossegurança, dos mitos e das realidades. Por fim, esperamos que essas reflexões possam contribuir para desfazer possíveis cicatrizes do passado nos entraves ainda existentes no diálogo entre jornalistas e cientistas para tornar a sociedade a maior beneficiada. 


\section{Bioinfor mática e/ou biologia computacional}

Ana Tereza Ribeiro de Vasconcelos

LABINFO, Laboratório Nacional de Computação Científica, MCT

Em meados dos anos 80, o Departamento de Energia ( $D$ oE) dos EU A deu início a um projeto cujo objetivo era 0 de produzir o mapeamento completo do genoma humano. Tal projeto denominou-se de Projeto G enoma H umano. As seqüências produzidas por este projeto, assim como todas as outras informações pertinentes, foram armazenadas em banco de dados computacionais que seriam a fonte de estudo para biologia e para medicina em um futuro próximo. 0 elevado volume de informação nestes bancos de dados induziram o uso de métodos computacionais sofisticados e eficientes para a análise das seqüências neles armazenadas. Surgem desta forma duas áreas de pesquisa (alguns autores consideram somente uma) que estão caminhando juntas: a Bioinformática, que pode ser descrita como a aquisição, análise e estoque de informação biológica, especificamente de ácidos nucléicos e proteínas; e a Biologia M olecular Computacional, que é a que estuda o desenvolvimento de al goritmos e programas computacionais para resolver problemas nesta área. Ambas têm crescido enormemente na última década, motivadas pelos projetos genomas em curso. Um dos objetivos fundamentais destas áreas é converter a informação contida na seqüência de nucleotídeos ou de proteínas (linguagem biológica) em conhecimento bioquímico e biofísico (funções estruturais, funcionais e evolutivas). $\mathrm{N}$ a realidade 0 que se procura é decodificar uma linguagem desconhecida, extraindo o seu significado biológico. Esta linguagem pode ser decomposta em frases (proteínas), palavras (motivos), e letras (nucleotídeos e/ou aminoácidos). 


\title{
A lei de patentes e pesquisa básica
}

\author{
Departamento de Biofísica Ambiental e Biotecnologia, Instituto de Biofísica, Universidade Federal do Rio de Janeiro
}

Para ficar claro como o sistema de patentes pode afetar a pesquisa básica, deve-se definir que direitos uma patente confere ao seu detentor, o qual terá direito de excluir terceiros de produzir, usar, colocar à venda ou importar 0 produto ou processo patenteado. D e forma simplista pode parecer que o patenteamento de um produto ou processo pode impedir seu uso em pesquisa básica, o que poderia comprometer o desenvolvimento de várias pesquisas. Porém, existe no sistema a prerrogativa do uso experimental, de modo que 0 uso de uma patente com finalidade de pesquisa é livre. N o Brasil a Lei 9.279/96, de 14 de maio de 1996, determina que algo para ser patenteável deve atender três pré-requisitos básicos: novidade absoluta, atividade inventiva e aplicação industrial. 0 artigo 10 estabelece que não se considera invenção ou modelo de utilidade "o todo ou parte de seres vivos naturais e materiais biológi cos encontrados na natureza, ou ainda que dela isolados, inclusive o genoma ou germoplasma de qualquer ser vivo natural e os processos biológicos naturais". Já o artigo 18 define o que não é patenteável: o todo ou parte dos seres vivos, exceto os microorganismos transgênicos que atendam os três requisitos de patenteabilidade, e que não sejam mera descoberta. Baseado no até então exposto fica claro que o patenteamento de genes, proteínas ou qualquer produto natural não é permitido no Brasil, por não serem considerados invenções. Porém, kits diagnósticos, composições farmacêuticas, composições inseticidas, por exemplo são patenteáveis, mesmo que contenham produtos naturais, ou parte de seres vivos. 0 uso experimental tem por finalidade estimular a pesquisa e a inovação, contudo, hoje nos Estados Unidos, vem havendo seu enfraquecimento jurídico, de modo que mesmo a pesquisa básica feita nas universidades vem sofrendo acionamentos judiciais por detentores de patentes. Além disso, patentes com escopo excessivamente amplos, como a do "D N A lixo" e do "oncomouse", mais o crescimento astronômico nos últimos anos no número de patentes de genes e seus produtos nos Estados U nidos podem comprometer seriamente o papel social das patentes como estímulo à pesquisa, causando o efeito inverso. $M$ ais grave ainda é 0 patenteamento por grupos de seus modelos experimentais, com a intenção de obter exclusividade sobre a pesquisa com esses modelos. 